\title{
Seismic Performance and Ice-Induced Vibration Control of Offshore Platform Structures Based on the ISO-PFD-SMA Brace System
}

\author{
Jigang Zhang, ${ }^{1}$ Zhehao Ma, ${ }^{1}$ Feifei Liu, ${ }^{1}$ Chunwei Zhang, \\ Pezhman Sharafi, ${ }^{2}$ and Maria Rashidi ${ }^{2}$ \\ ${ }^{1}$ School of Civil Engineering, Qingdao University of Technology, Qingdao 266033, China \\ ${ }^{2}$ Center for Infrastructure Engineering, Western Sydney University, Locked Bag 1797, Penrith South DC, NSW 2751, Australia \\ Correspondence should be addressed to Jigang Zhang; jigangzhang@126.com
}

Received 14 July 2016; Revised 31 October 2016; Accepted 29 November 2016; Published 15 January 2017

Academic Editor: Ying Wang

Copyright (C) 2017 Jigang Zhang et al. This is an open access article distributed under the Creative Commons Attribution License, which permits unrestricted use, distribution, and reproduction in any medium, provided the original work is properly cited.

Pall-typed frictional damper (PFD) has higher capacity of energy dissipation, whereas shape memory alloy (SMA) has excellent superelastic performance. Therefore, combining PFD and SMA together as a brace system has a great prospect in vibration control of structures. This paper investigates the performance of offshore platform with three structural configurations including the SMA brace system, the ISO-SMA (where ISO stands for isolation) brace system, and the ISO-PFD-SMA brace system, which are subjected to seismic and ice-induced excitations. In this study, PFD-SMA brace system is installed on the isolation layer of jacket platform, which is under earthquake excitations and ice loading. Then, the reduction of vibration is evaluated by using ANSYS program. The results show that the PFD-SMA brace system is useful in reducing the seismic response and ice-induced response of offshore platform structures; meanwhile, it also demonstrates excellent energy dissipation and hysteretic behavior.

\section{Introduction}

In 1947, the world's first self-contained steel jacket offshore platform was built in the gulf of Mexico. It reached in a new era of exploitation of ocean. Following the rapid development of offshore petroleum industry, nearly 10000 offshore platforms are widely used in many fields at present, mainly in petroleum engineering. For the sake of better adaptation to the social and economic development and ensuring the supply of energy, many offshore platforms are built. Because of severe working environment and complicated load condition, its security and stability must be concerned.

Offshore platforms are subjected to different environmental loads during their life time, such as earthquake, wave, wind, and ice. Particularly, seismic load should be taken into account comprehensively due to its unpredictability and randomness. Therefore, it is necessary to ensure the platform does not fall in the earthquake and decrease the loss of disaster to a minimum. JZ20-2MUQ offshore platform was built in the Bohai gulf, which is in earthquake zone.
In the higher latitudes, ice load is taken as design control load based on estimation. Intensive vibration induced by continuous crushing of ice will influence security and comfort of workers. At the same time, the degradation of resistance induced by the excessive and large amplitude vibration may lead to the fatal results. In 1964, two platforms that were completed in 1962-1963 collapsed, due to sea ice in Cook Inlet in Alaska; in 1969, a new offshore platform collapsed under the repeated hit of large ice loads (average ice thickness of flat ice was about $60 \mathrm{~cm}$; the biggest thickness was above $1 \mathrm{~m}$ ) [1].

Liaodong Bay is one of the important producing oil regions in the Bohai oilfield which is located at the unique sea ice covered waters in our country. At the same time, Liaodong Bay is the worst ice blockages along the Bohai Sea. Bohai Oilfield Services limited company preformed the observation of sea ice; the maximum acceleration of deck on JZ20-2MUQ platform hits a peak of $3-4 \mathrm{~m} / \mathrm{s}^{2}(300-400 \mathrm{gal})$.

Shape memory alloys (SMA) are metallic alloys that can withstand great strains, while recovering their initial state after unloading or by heating, without permanently 
deformation due to their excellent superelastic performance. Research efforts have been made to use SMA based materials or devices for reducing earthquake damage of civil structures [2-8]: base isolation systems [2, 3], dampers [4], bracing systems for structure [5, 6], application in bridge [7], and beam-column connections [8]. These studies demonstrated the feasibility and effectiveness of SMA as a structural selfcentering and damping component. Since Pall-typed frictional damper (PFD) has higher capacity of energy dissipation [9], shape memory alloy (SMA) has excellent superelastic performance [10]. In this work, a finite element model of JZ20-2MUQ platform with PFD-SMA brace system is built, and time history response of the model impacted by Tianjin, El Centro, and Taft seismic wave is analyzed. Simultaneously, ice-induced vibration control is also conducted. In order to have a comparative study more comprehensively, based on the results of simulation, seismic behavior on JZ202MUQ offshore platform with and without PFD-SMA brace system is contrasted through the finite element analysis software ANSYS. The results show that PFD-SMA brace system has good energy dissipation and good self-centering performance.

\section{Structure Parameters and FEM Model of JZ20-2MUQ Platform}

2.1. Structure Parameters of JZ20-2MUQ Platform. JZ202MUQ offshore platform is located in the shallow waters in Bohai bay. The design depth is $15 \mathrm{~m}$. JZ20-2MUQ platform consists of jacket, jacket cap, pillar, deck (including two device layers), and living quarters [12]. Its foundation is composed of four jacket pipes and driven into the seabed through the piles. The photo of JZ20-2MUQ is shown in Figure 1.

The main parameters of JZ20-2MUQ are shown as follows. This platform is mainly made of steel with density of $7.85 \mathrm{~kg} / \mathrm{m}^{3}$, Young's modulus of $2.10 \times 10^{5} \mathrm{Mpa}$, and Poisson ratio of 0.3 ; the length of pipe below the mud line is equivalent to 6.4 times the diameter of pipe $(L=6.4 ; D=8.8 \mathrm{~m})$, so the overall height is about 64 meters; The total mass of structure is around 2000 tons, and the size of guide pipes is $\phi 59.5$ $\times 1.25$ (in). The elevation view of JZ20-2MUQ is shown in Figure 2.

2.2. FEM Model of JZ20-2MUQ and Arrangement of PFDSMA Bracing System. A 3D frame model of original platform is created by finite element analysis software ANSYS as shown in Figure 4; the steel beams are modeled with ANSYS BEAM188. The mass is including deck and other masses which is used by ANSYS MASS21 [13]. Based on code for seismic design of buildings (GB50011-2001) in China, the gravity load value is determined by the combinational coefficient, and all masses are concentrated on the joints of member bars.

PFD-SMA brace system consists of SMA supports and Pall-typed friction damper; the connection of SMA brace and PFD ordinary steel plate is bolted joint. Figure 3 shows the PFD-SMA brace system. In order to improve antivibration character of the platform structure, we set two SMA braces
TABLE 1: Measured frequencies and damping ratio of JZ20-2MUQ platform structure.

\begin{tabular}{lccc}
\hline Mode number & 1 & 2 & 3 \\
\hline Frequency (Hz) & & & \\
$\quad$ Measured 1 [11] & 0.90 & 1.05 & 1.15 \\
$\quad$ Measured 2 [11] & 0.85 & 1.12 & \\
Damping ration [11] (\%) & & $4.0 \sim 5.5$ & \\
\hline
\end{tabular}

TABLE 2: Calculated natural frequencies of JZ20-2MUQ platform structure.

\begin{tabular}{lc}
\hline Mode number & Frequency $(\mathrm{Hz})$ \\
\hline 1 & 0.742 \\
2 & 0.787 \\
3 & 0.792 \\
4 & 1.481 \\
5 & 1.604 \\
6 & 2.247 \\
7 & 2.657 \\
8 & 2.861 \\
9 & 3.008 \\
10 & 3.091 \\
\hline
\end{tabular}

between living deck and jacket cap on the model, as shown in Figure 5. The SMA bracing is modeled with ANSYS SOLID185, and the Pall friction damper is modeled with the combination of ANSYS COMBIN40, BEAM4, and LINK8.

2.3. Dynamic Characteristic of JZ20-2MUQ. Based on the measurement in the field, the first three frequencies and damping ratio of JZ20-2MUQ platform have been acquired (summarized in Table 1).

Structural modal identification based on environmental excitation is available, using measured data to obtain the modal parameters. Accordingly, though the modal analysis, the dynamic characteristics of JZ20-2MUQ platform are analyzed; the first ten nature frequencies of model are gained and listed in Table 2. It could be found that the first three frequencies and damping ratio measured in the field are larger than those calculated, compared with the results in Table 1. The differences between the two could be attributed to several reasons, mainly caused by the effective mass values of the structure which are higher than simulated model due to the contribution of nonstructural components.

\section{Seismic and Ice-Induced Vibration Analysis of JZ20-2MUQ with PFD-SMA Bracing System}

3.1. Seismic Analysis. By using ANSYS program, the dynamic finite element analytic model of the JZ20-2MUQ platform with SMA bracing is established. The numerical simulations are executed. Seismic input is modeled by using three different earthquake excitations including Tianjin (1976, EW), 


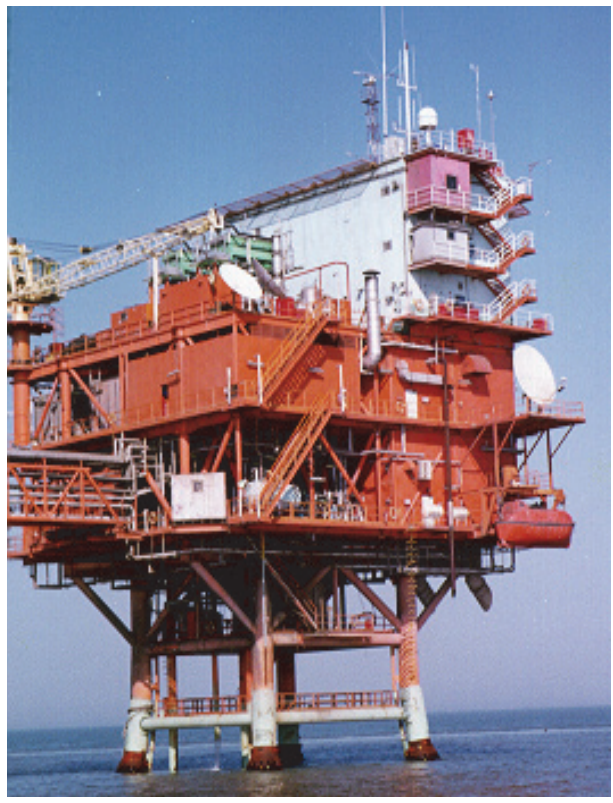

Figure 1: Photo of JZ20-2MUQ.

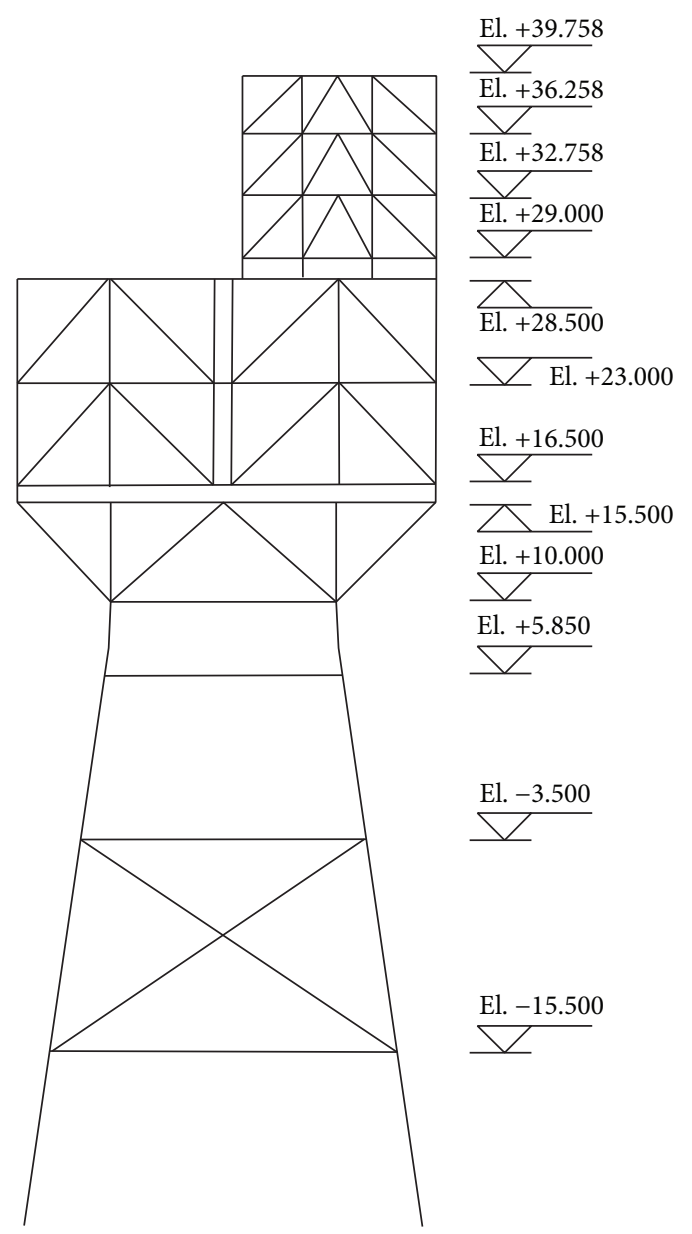

FIGURE 2: Elevation view of JZ20-2MUQ. 


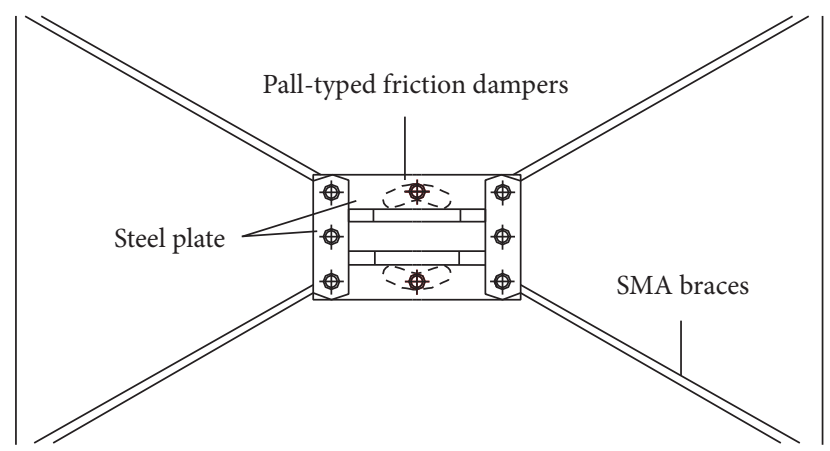

FIGURE 3: PFD-SMA brace system.

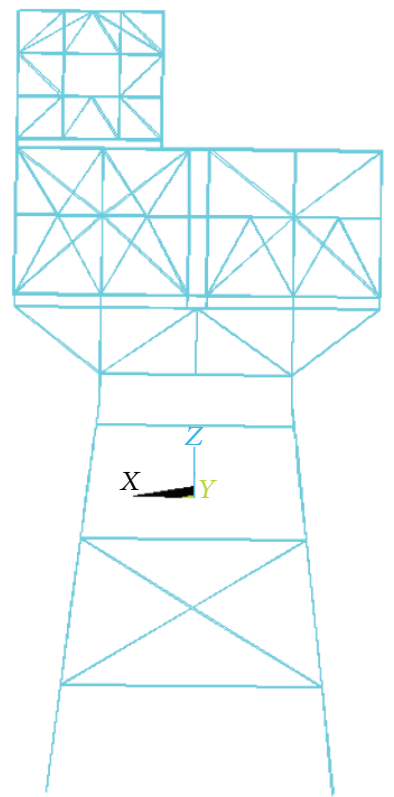

FIGURE 4: FEM of original structure.

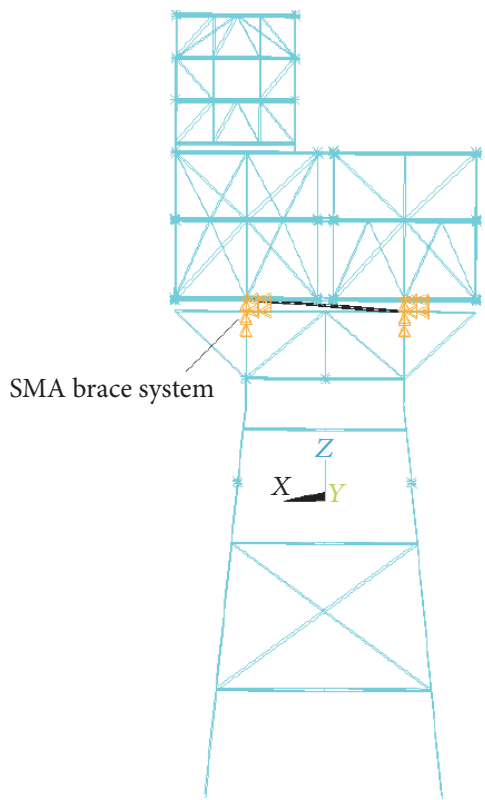

FIGURE 5: FEM of structure with SMA brace system. 


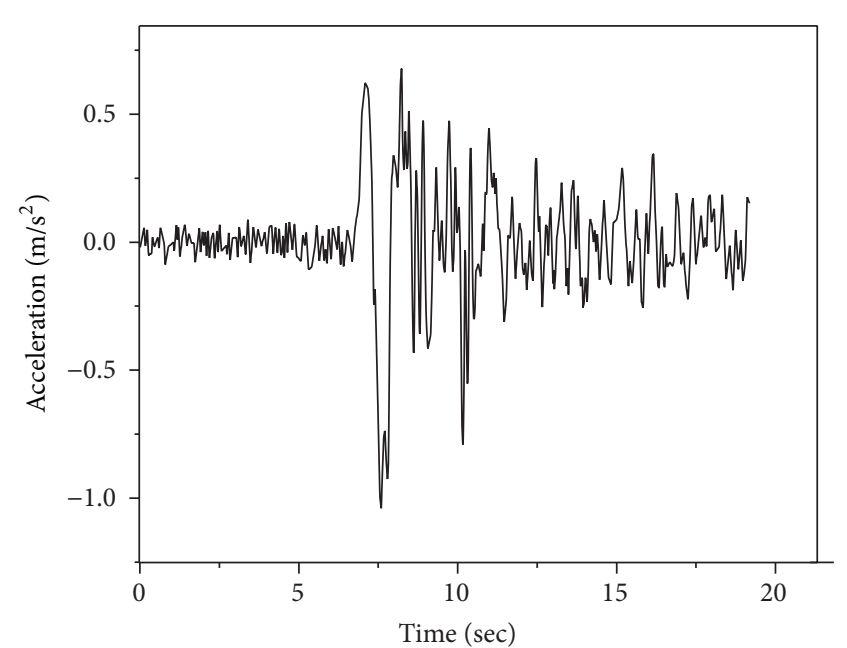

(a) Tianjin (1976, EW)

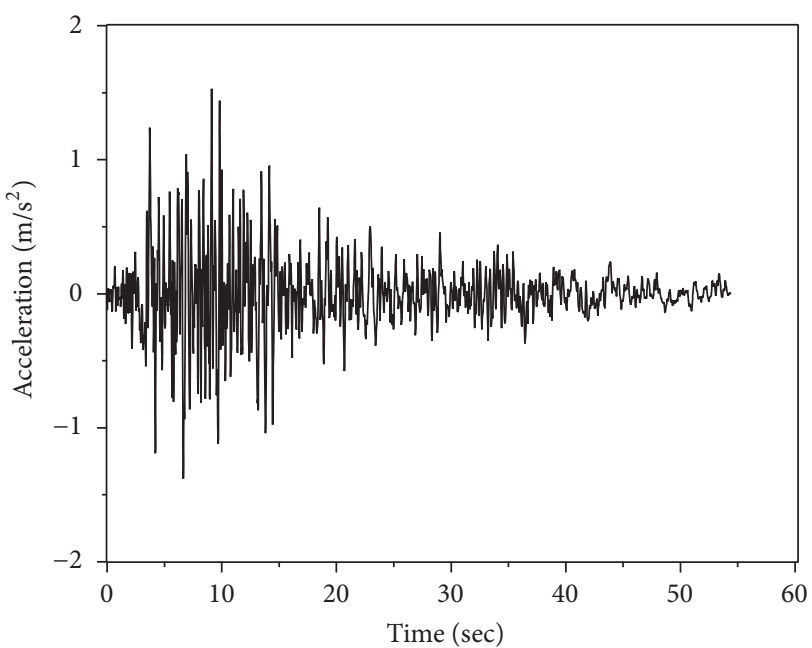

(b) Taft $(1952, \mathrm{~N} 21 \mathrm{E})$

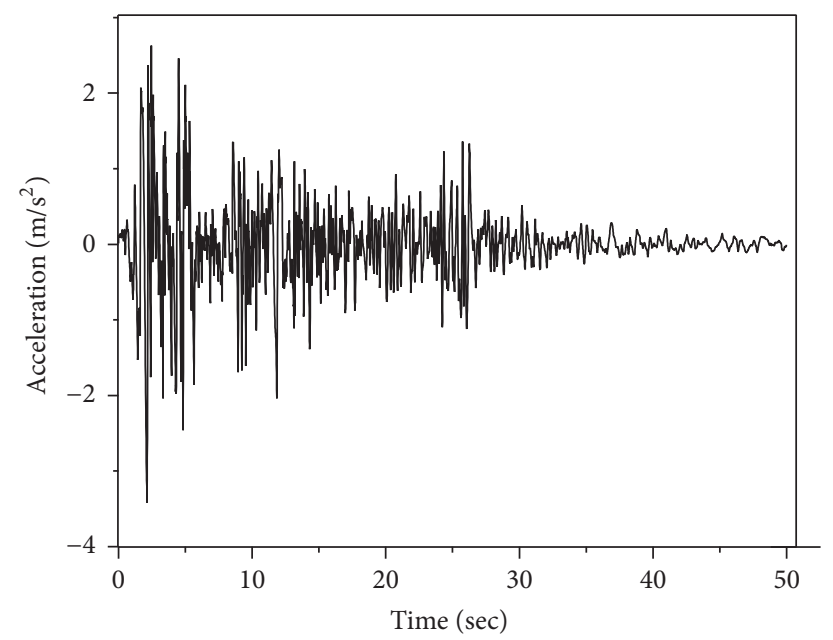

(c) El Centro $(1940, \mathrm{SN})$

FIgURE 6: Acceleration time history curves of three earthquake excitations.

Taft (1952, N21E), and El Centro (1940, SN); their acceleration time history curves are shown in Figure 6.

The dynamical characteristics contrastive analysis of platform with and without SMA bracing system is analyzed, and seismic response contrastive analysis is calculated by the method of elastic time history response of systems [14]. The response of the structure to ground motion under three earthquake excitations was carried out, which is shown in Table 3. The ground acceleration is applied in $X$-direction modes. From Table 3, it can be found that the reduction of vibration under three earthquake excitations is not obvious; the maximum deformation of jacket cap reduces by only $4.3 \%$, even though it reduces by $1 \%$ or almost zero percent under the Tianjin waves. Besides, the maximum acceleration of top deck and lower deck decreases slightly, and the percentage of reduction is $10.7 \%$ and $30.8 \%$, respectively. Particularly, jacket plays a crucial role in maintaining stability and security of the entire platform. Once jacket oversized displacement leads to the collapses of platform, the subsequent consequence is unbearable. Furthermore, the top deck is living quarters, and there is no doubt that large acceleration will affect the level of comfort of the workers on platform. Thus, such a small effect of mitigating vibration will not be able to meet the requirements obviously. Figure 7 shows the time history curves of the maximum displacement on jacket cap. Figures 8 and 9 show the time history curves of maximum acceleration on the top deck and the lower deck, respectively.

Considering the above numerical analysis, it is found that SMA bracing system is not efficient in reducing the response of vibration under earthquake excitation, compared with uncontrolled structure. The reason why SMA bracing could not give full play to their potential is that the overall stiffness of the platform structure is too large, and the deformation is too small. Thus, increasing the deformation of SMA and its capacity of energy dissipation to achieve the desired effect is considered. In order to enhance the energy consumption, the damping isolation system is placed between the bottom of 


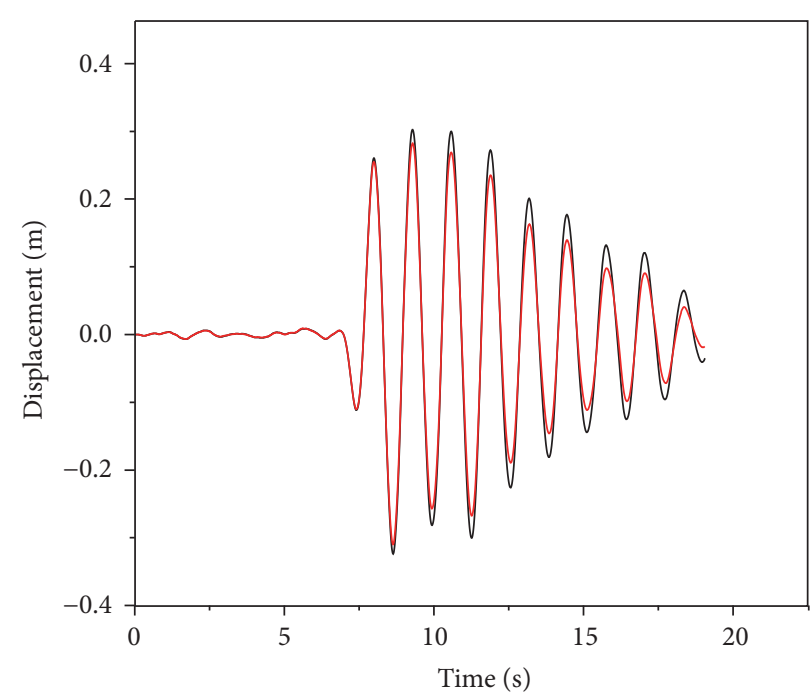

Uncontrolled

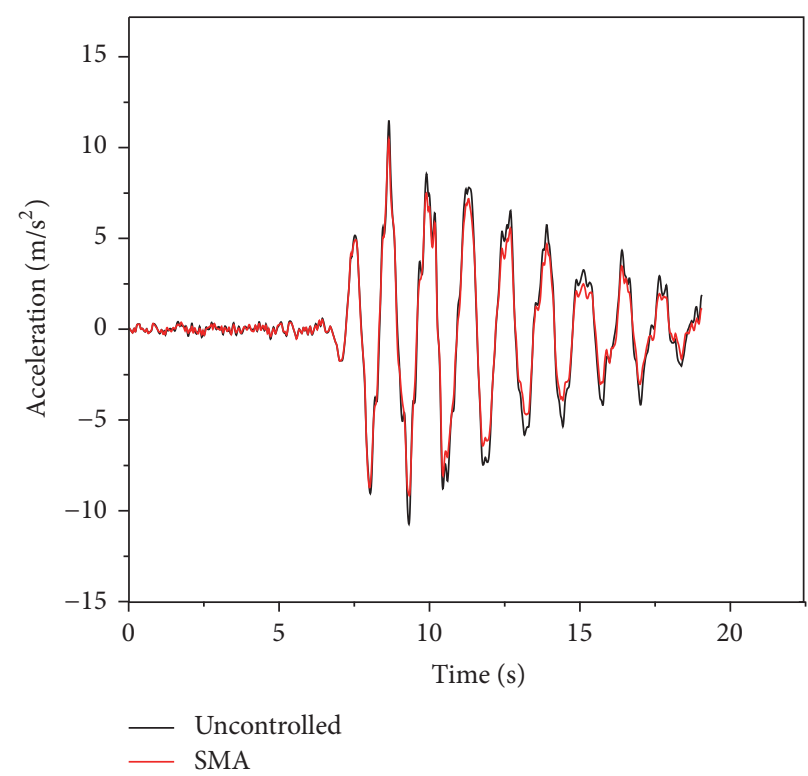

(b) Acc. of lower deck

(a) Dis. of jacket cap

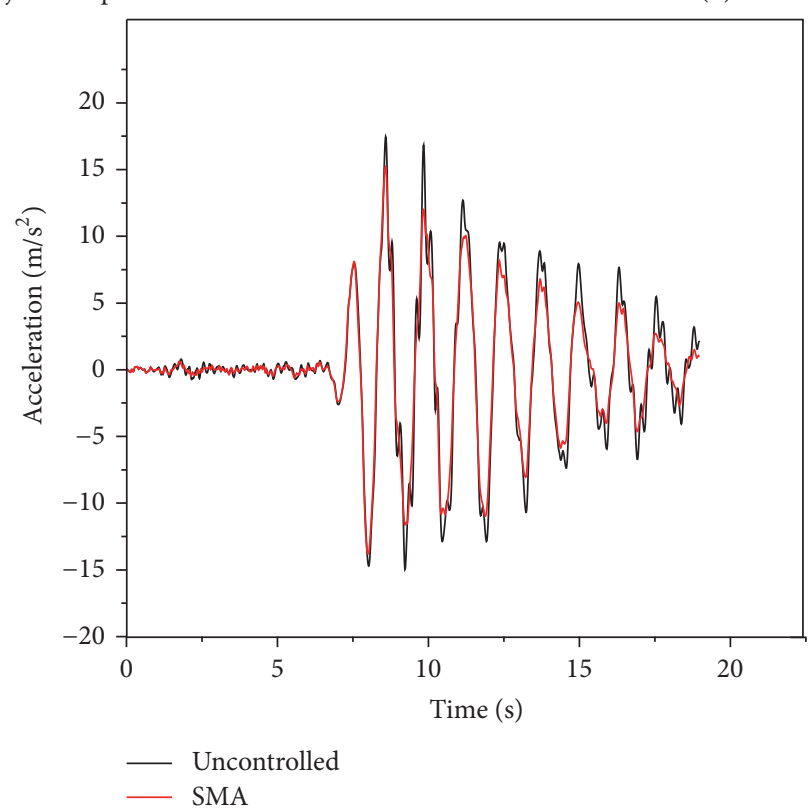

(c) Acc. of top deck

FIGURE 7: Computational response of JZ20-2MQU model under Tianjin earthquake excitation.

TABLE 3: Maximum test results of earthquake excitation of the platform with SMA brace.

\begin{tabular}{|c|c|c|c|c|}
\hline Earthquake & Structural type & $\begin{array}{l}\text { Displacement of jacket } \\
(\mathrm{cm})\end{array}$ & $\begin{array}{l}\text { Acceleration of lower deck } \\
\left(\mathrm{cm} / \mathrm{s}^{2}\right)\end{array}$ & $\begin{array}{l}\text { Acceleration of top deck } \\
\left(\mathrm{cm} / \mathrm{s}^{2}\right)\end{array}$ \\
\hline \multirow[b]{2}{*}{ Tianjin } & Original & 30.3 & 1150 & 1750 \\
\hline & SMA & $\begin{array}{c}30.3 \\
(0.043) \\
\end{array}$ & $\begin{array}{c}1050 \\
(0.087) \\
\end{array}$ & $\begin{array}{c}1520 \\
(0.131) \\
\end{array}$ \\
\hline \multirow[b]{2}{*}{ TAFT } & Original & 10.2 & 747 & 914 \\
\hline & SMA & $\begin{array}{c}9.76 \\
(0.043) \\
\end{array}$ & $\begin{array}{c}667 \\
(0.107) \\
\end{array}$ & $\begin{array}{c}829 \\
(0.093) \\
\end{array}$ \\
\hline \multirow[b]{2}{*}{ El Centro } & Uncontrolled & 9.52 & 589 & 1066 \\
\hline & SMA & $\begin{array}{c}9.29 \\
(0.024)\end{array}$ & $\begin{array}{c}576 \\
(0.022)\end{array}$ & $\begin{array}{c}738 \\
(0.308)\end{array}$ \\
\hline
\end{tabular}

Note: the figure in brackets is the percentage of effectiveness of mitigating vibration which is equal to (uncontrolled structure - control structure)/uncontrolled structure). 


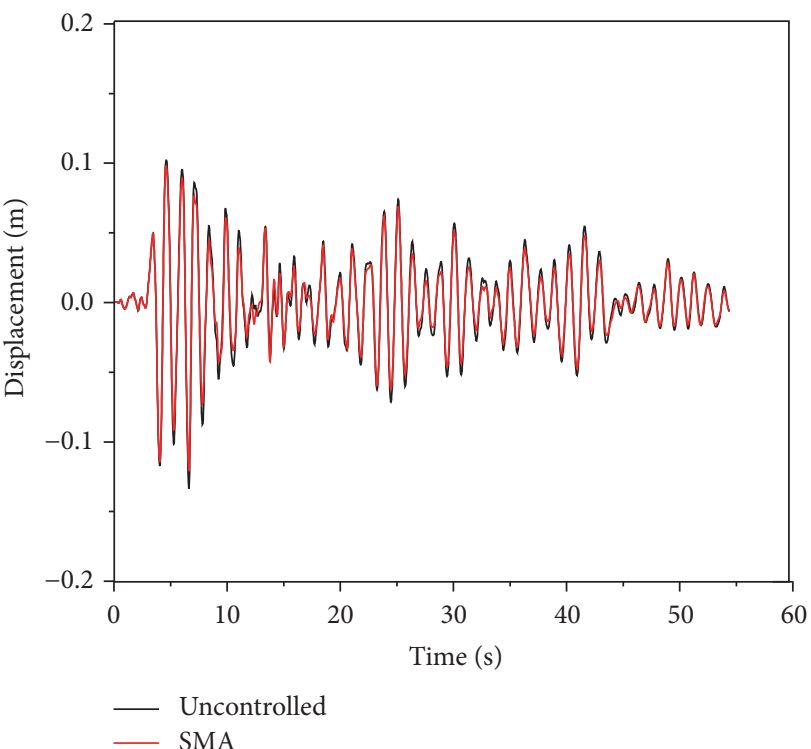

(a) Dis. of jacket cap

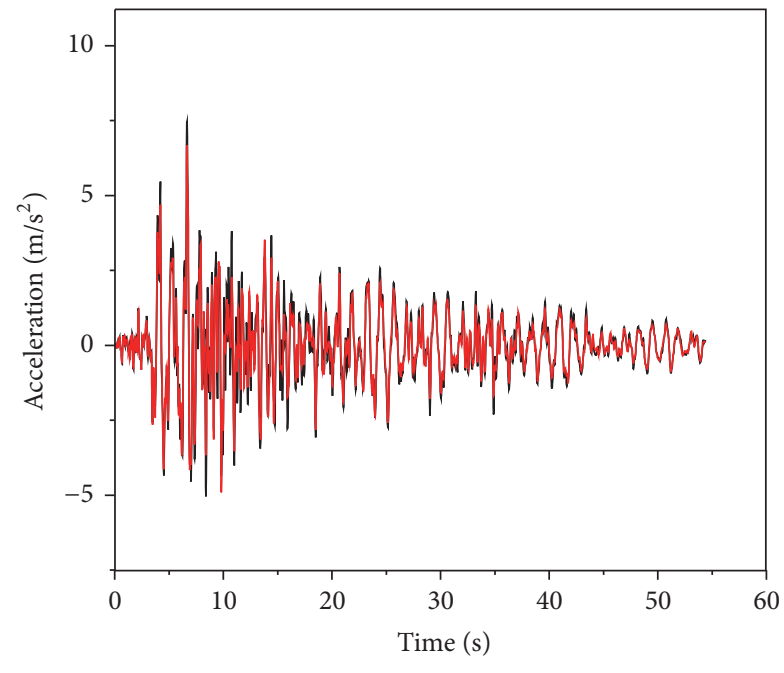

Uncontrolled SMA

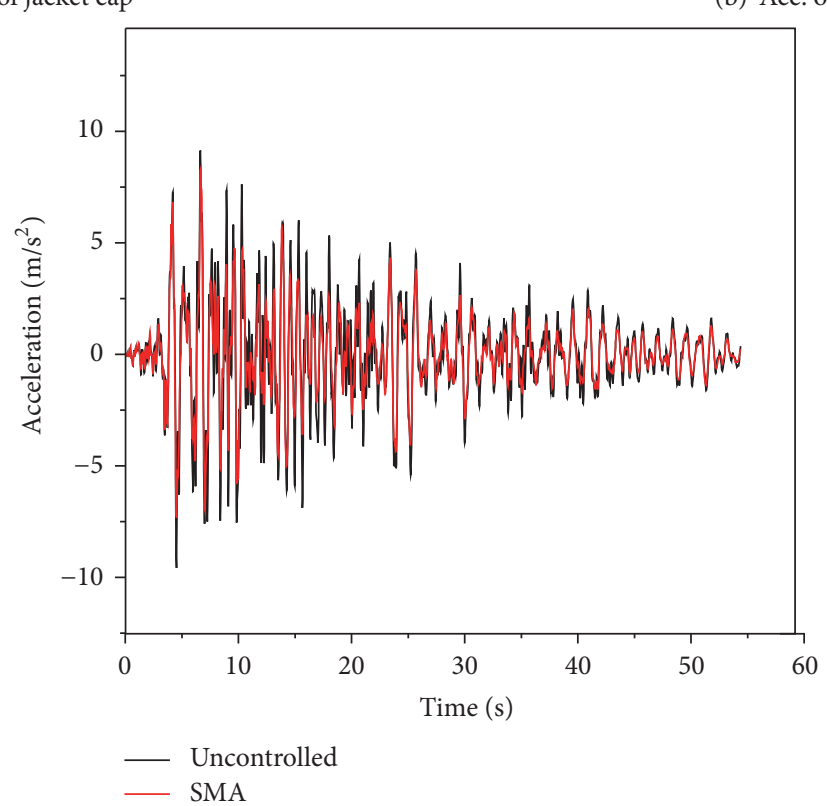

(c) Acc. of top deck

FIGURE 8: Computational response of JZ20-2MQU model under Taft earthquake excitation.

the deck and the top of the jacket structure [15]. The rubber layer is modeled by ANSYS COMBIN14 and CONBIN40. The horizontal forces are analyzed mostly by the former, and the latter undertakes vertical forces mainly. COMBIN14 has longitudinal or torsional capability in one-, two-, or threedimensional application; COMBIN40 is a combination of a spring-slider and damper in parallel, coupled to a gap in series. In the meantime, two SMA supports and two PFDSMA supports are set in isolation layer between living deck and jacket cap on the model, respectively, as shown in Figures 10 and 11.

The numerical simulations are conducted for platform model including three structure styles: the uncontrolled structure, the structure with isolation layer and SMA bracing system (called ISO-SMA structure), and the structure with isolation layer and PFD-SMA bracing system (called ISOPFD-SMA structure).

The response of the ISO-SMA structure under three earthquake excitations is carried out and summarized in Table 4 . Figure 12 shows the time history curves of the maximum displacement on jacket cap. Figures 13 and 14 show the time history curves of maximum acceleration on the top deck and the lower deck, respectively.

According to Table 4, the results of simulated calculation indicate that each different kind of control scheme could reduce the response of earthquake excitation. The ISO-SMA 


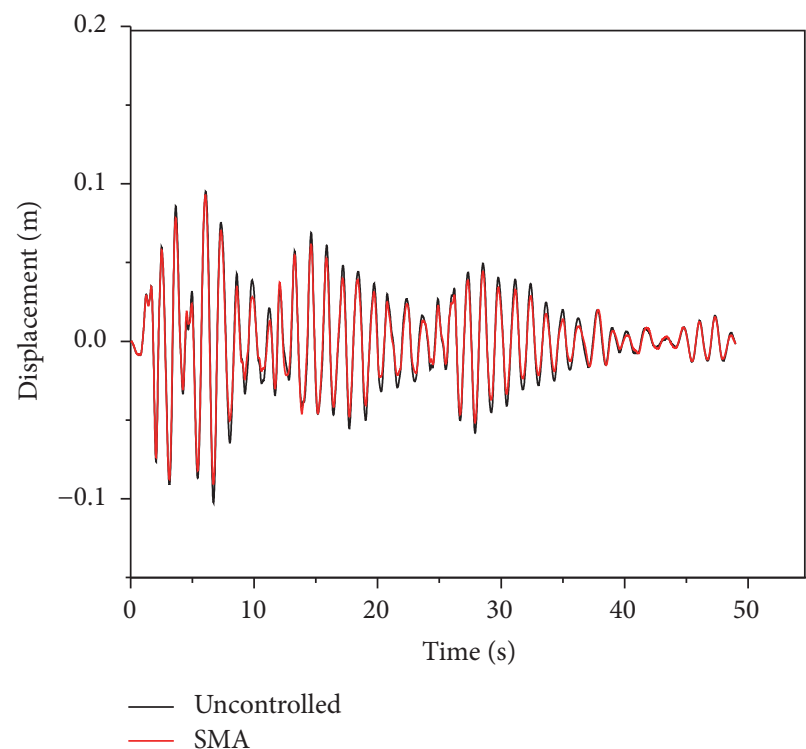

(a) Dis. of jacket cap

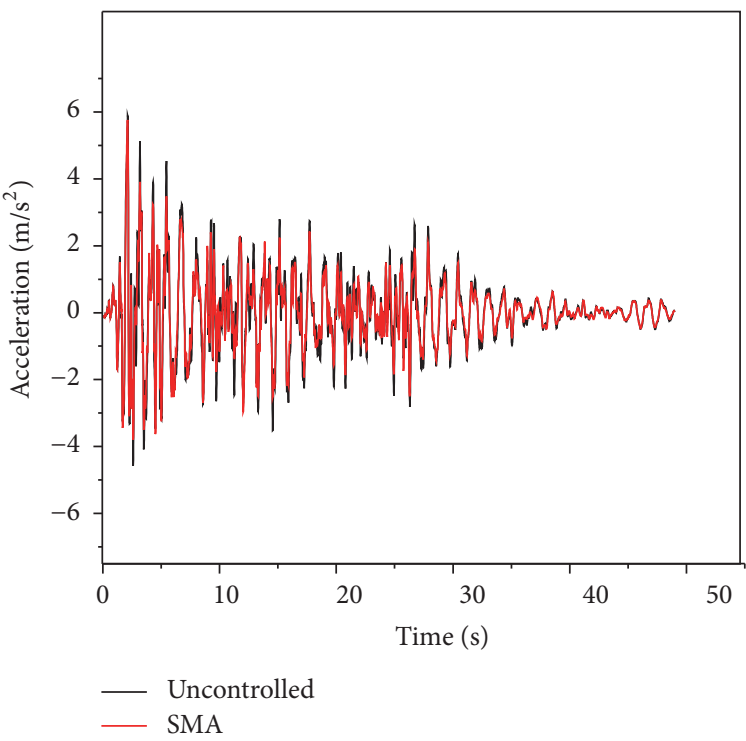

(b) Acc. of lower deck

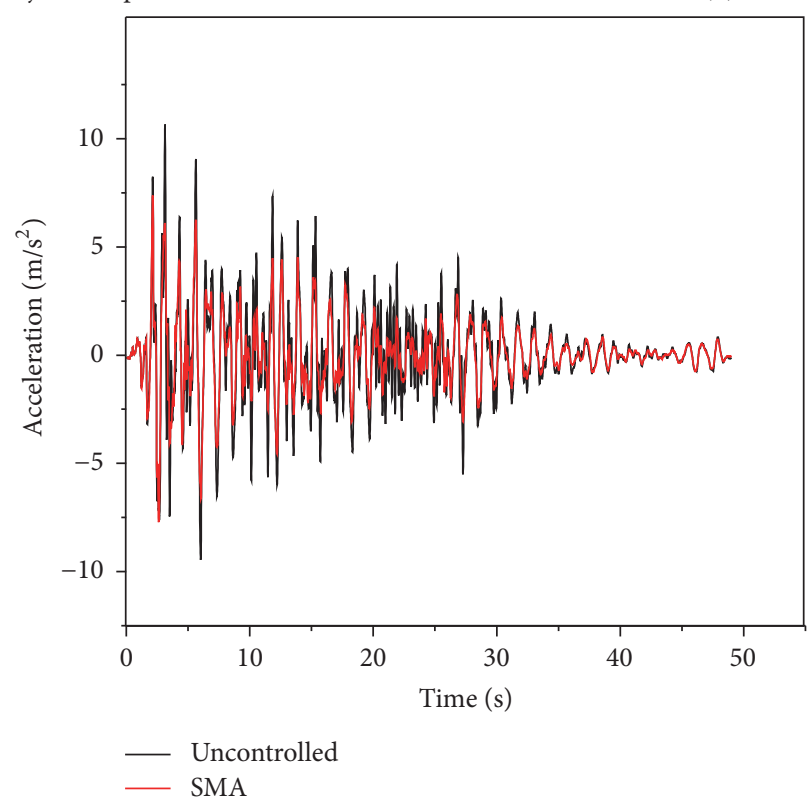

(c) Acc. of top deck

FIGURE 9: Computational response of JZ20-2MQU model under El Centro earthquake excitation.

TABLE 4: Maximum test results of earthquake excitation of the platform.

\begin{tabular}{lcccc}
\hline Earthquake & Structural type & Displacement of jacket $(\mathrm{cm})$ & Acceleration of lower deck $\left(\mathrm{cm} / \mathrm{s}^{2}\right)$ & Acceleration of top deck $\left(\mathrm{cm} / \mathrm{s}^{2}\right)$ \\
\hline \multirow{2}{*}{ Tianjin } & Uncontrolled & 30.3 & 1150 & 1750 \\
& ISO-SMA & $7.84(0.741)$ & $558(0.515)$ & $638(0.635)$ \\
& ISO-PFD-SMA & $2.26(0.925)$ & $444(0.614)$ & $467.9(0.733)$ \\
\hline \multirow{2}{*}{ TAFT } & Uncontrolled & 10.2 & 747 & $411(0.550)$ \\
& ISO-SMA & $4.6(0.549)$ & $377(0.495)$ & $516.6(0.436)$ \\
\hline \multirow{2}{*}{ El Centro } & ISO-PFD-SMA & $2.0(0.804)$ & $504.2(0.325)$ & 1066 \\
& Uncontrolled & 9.52 & 589 & $468(0.561)$ \\
& ISO-SMA & $5.68(0.403)$ & $398(0.334)$ & $470(0.559)$ \\
\hline
\end{tabular}

Note: the figure in brackets is the percentage of effectiveness of mitigating vibration which is equal to (uncontrolled structure - control structure)/uncontrolled structure). 


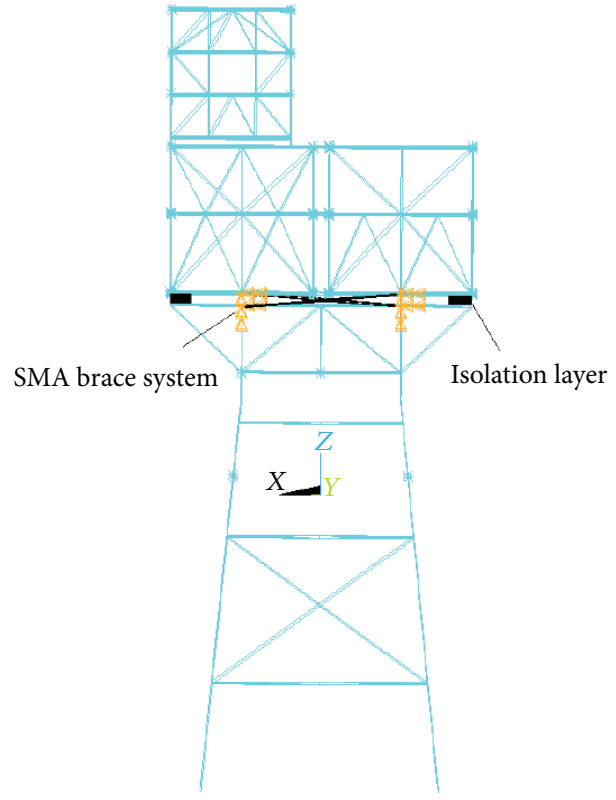

FIGURE 10: FEM of structure with ISO-SMA.

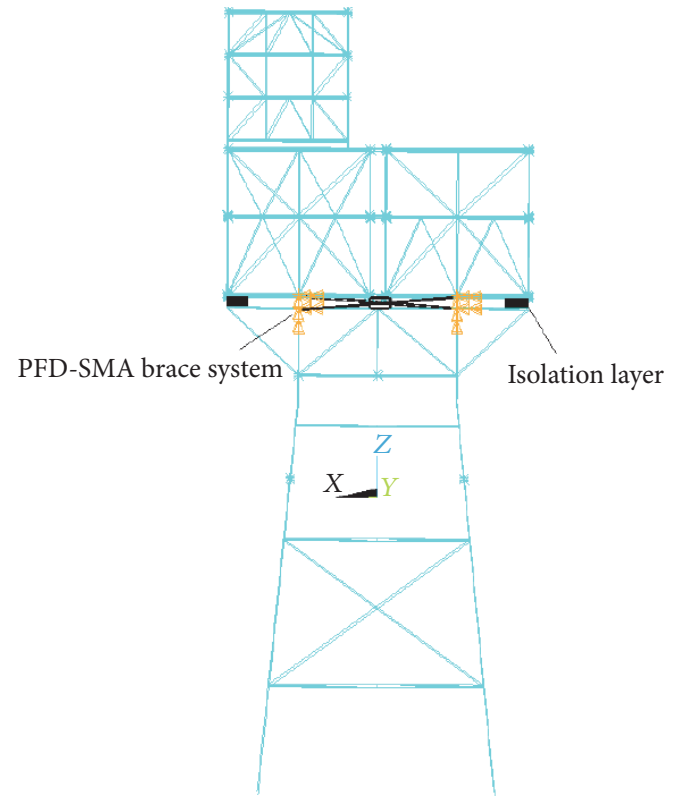

FIGURE 11: FEM of structure with ISO-PFD-SMA.

system is an effective way to reduce the seismic responses of platform structure under the earthquake motion input. The proportional reduction of maximum relative displacement of jacket cap is all over $40.3 \%$ in three circumstances. And the percentage of reduction is up to $74.1 \%$ under Tianjin seismic excitation. Both the maximum accelerations of top deck and lower deck are reduced by at least $33.4 \%$ in the same excitations.

However, it is noticed that ISO-PFD-SMA system is superior to the ISO-SMA system from Table 4. It even achieves a $92.5 \%$ reduction on the maximum displacement of jacket under Tianjin seismic excitation, $18.4 \%$ higher than ISO-SMA. Under Taft, ISO-PFD-SMA system also has a better control effect on the maximum displacement of jacket; the percentage of reduction is up to $80.4 \%, 25 \%$ higher than ISO-SMA. From these results, ISO-PFD-SMA system possesses obvious effects on displacement suppression. Although ISO-PFD-SMA system is slightly lower on the acceleration control, compared to ISO-SMA, it matches security and comfort requirements indeed. Moreover, it could be found 


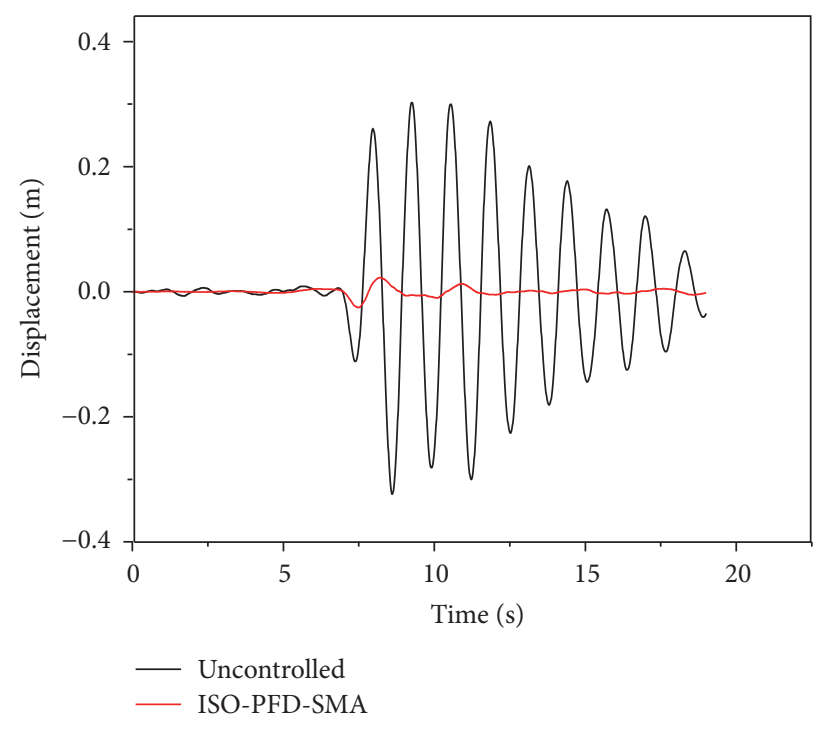

(a) Dis. of jacket cap

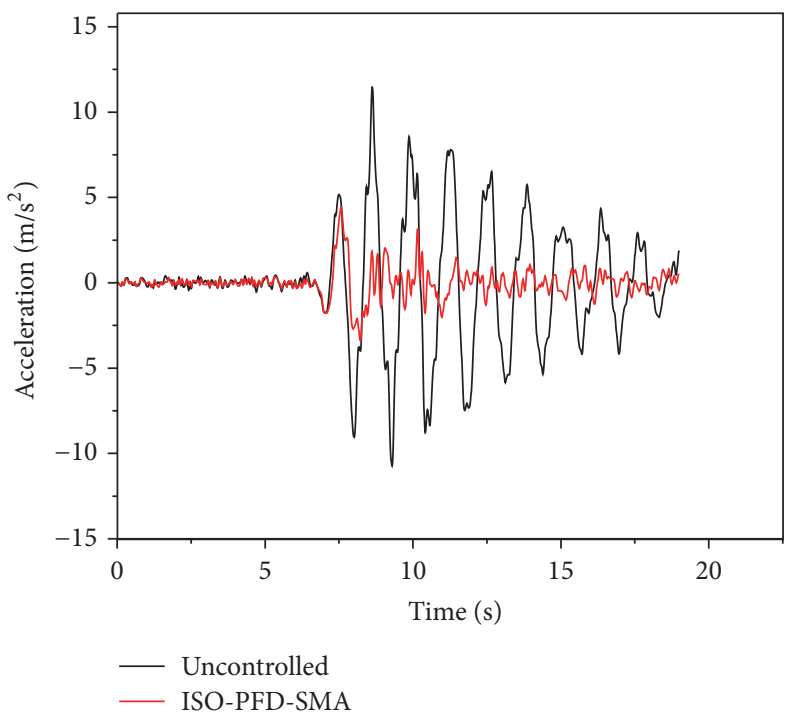

(b) Acc. of lower deck

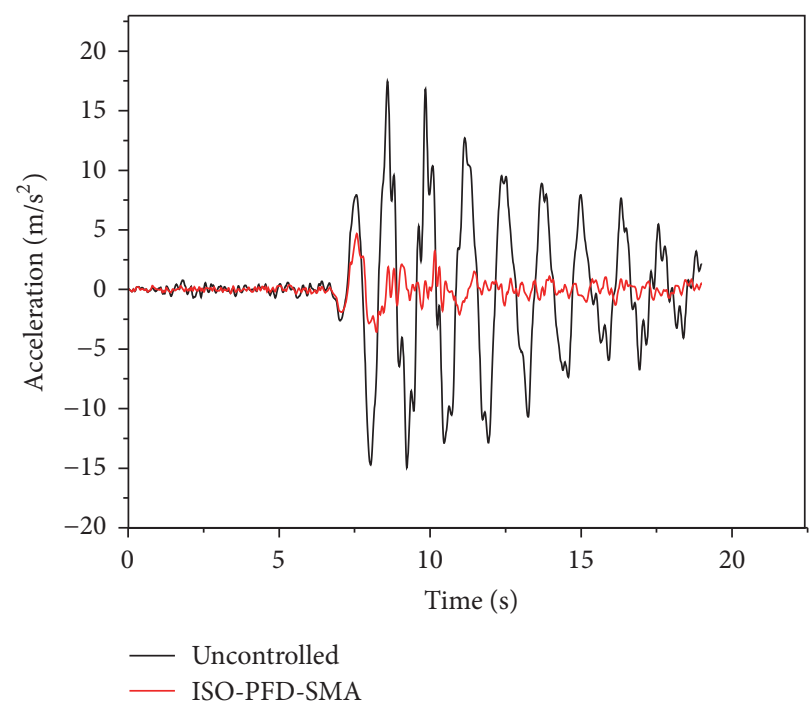

(c) Acc. of top deck

FIGURE 12: Computational response of JZ20-2MQU model under Tianjin earthquake excitation.

that the structure with ISO-PFD-SMA brace system nearly returns to the initial position after the seismic excitation, which confirms that this system has a good self-centering capability.

3.2. Ice-Induced Vibration Analysis. With the land on three sides, Bohai gulf is located on the east coast of mid-latitude and mainly influenced by monsoon circulation. Since it is isolated, less heat is exchanged with seas off the semiclosed bays. In winter, Bohai gulf will be affected by strong Mongolia cold high pressure. Additionally, the water of the Bohai is not very salty, because many fresh rivers flow into it. Thus, it freezes more easily. Considering the above, Bohai bay is one of the sea areas with serious ice condition in China [16]. Since last century, ice condition on a large scale has happened seven
TABLE 5: The basic data of ice condition in the Bohai bay.

\begin{tabular}{lccccc}
\hline \multirow{2}{*}{ Period } & \multicolumn{2}{c}{ Fast ice } & \multicolumn{3}{c}{ Sea ice } \\
& $\begin{array}{c}\text { Coverage } \\
(\mathrm{km})\end{array}$ & $\begin{array}{c}\text { Thickness } \\
(\mathrm{cm})\end{array}$ & $\begin{array}{c}\text { Coverage } \\
(\mathrm{km})\end{array}$ & $\begin{array}{c}\text { Thickness } \\
(\mathrm{cm})\end{array}$ & $\begin{array}{c}\text { Speed } \\
(\mathrm{m} / \mathrm{s})\end{array}$ \\
\hline Nov. to Mar. & $5-10$ & $30-40$ & $110-130$ & $20-30$ & $0.4-0.8$ \\
\hline
\end{tabular}

times in this area. In the winter of 1968, one platform on Bohai gulf collapsed, because of the worst ice blockages along Bohai Sea. Table 5 shows the basic data of ice condition in the Bohai bay. The model simulation uses the actual three bending ices and three pushing ices. To save space, one bending ice and one pushing ice time history curves are shown in Figure 15. 


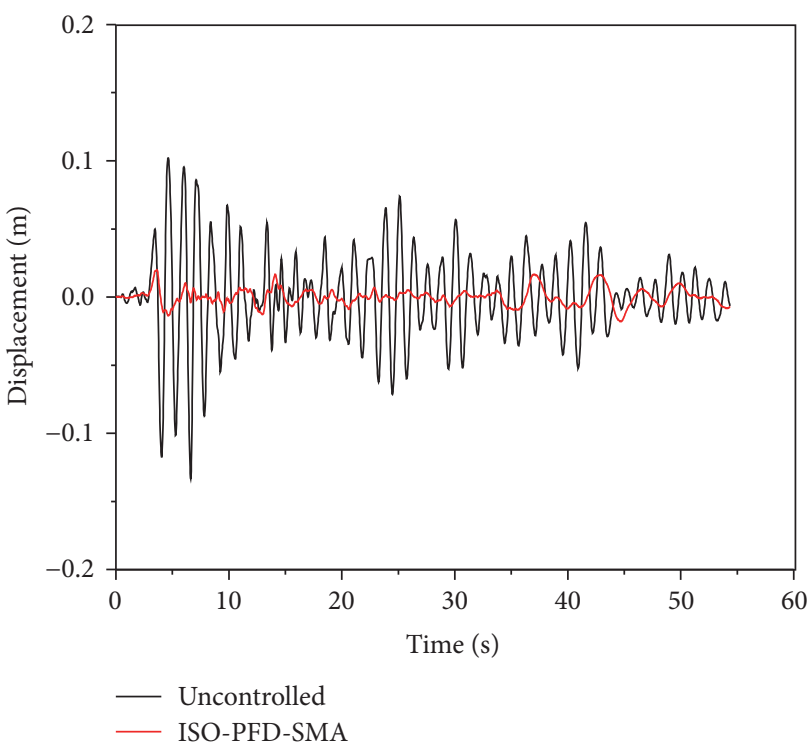

(a) Dis. of jacket cap

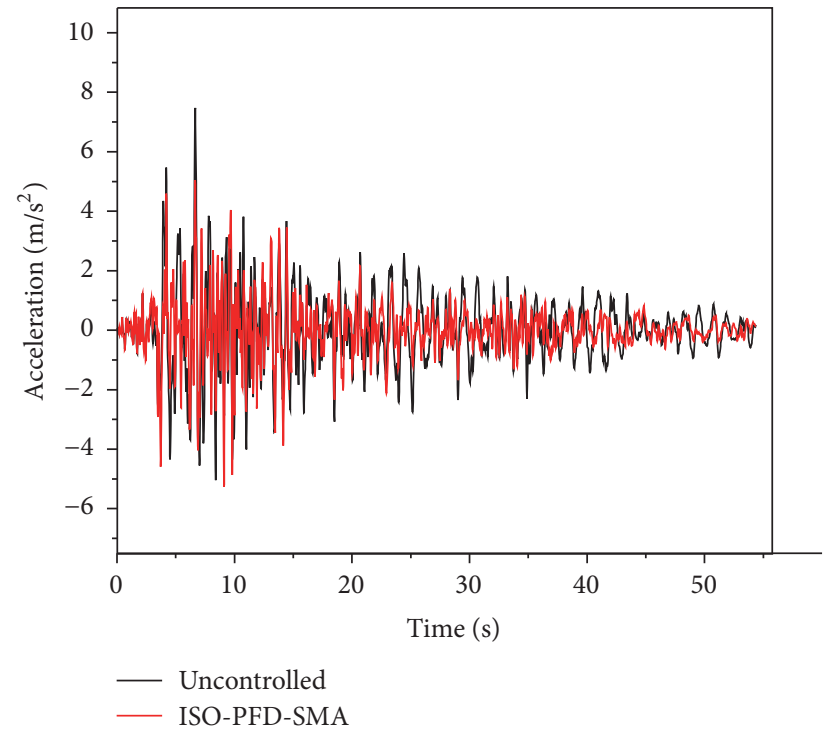

(b) Acc. of lower deck

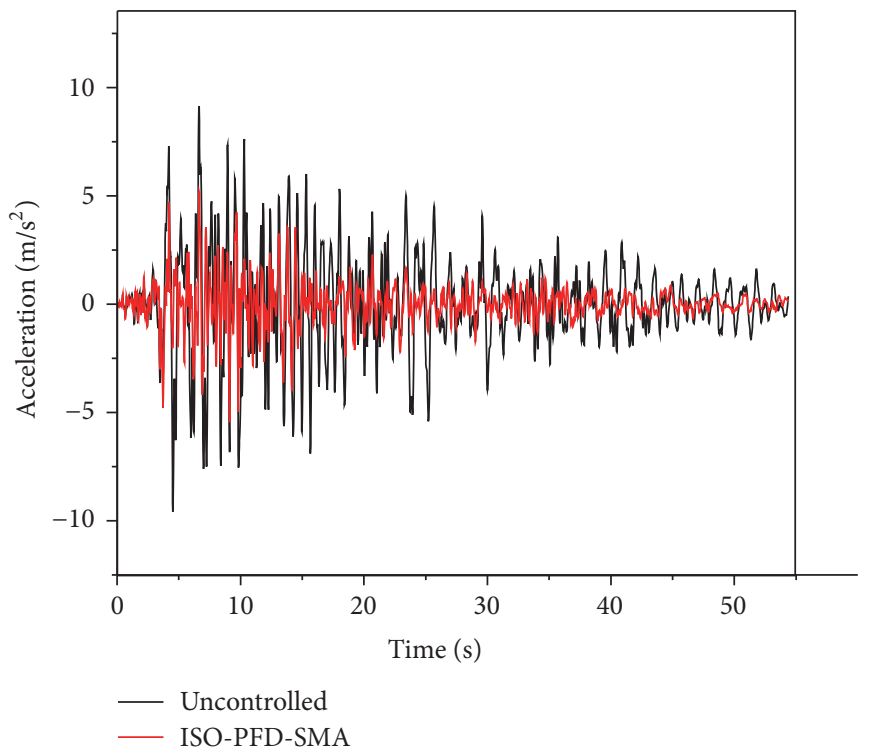

(c) Acc. of top deck

FIGURE 13: Computational response of JZ20-2MQU model under Taft earthquake excitation.

To validate the effectiveness of PFD-SMA bracing system in vibration control under the ice loads, numerical analysis has been conducted by ANSYS software. The ice-induced vibration simulation uses three platform structure styles including the uncontrolled structure, the structure with ISOSMA bracing system, and the structure with ISO-PFD-SMA bracing system.

The responses are shown in Table 6. According to the results, the peak response of the structure with ISO-PFDSMA is significantly reduced. From Table 6 , the maximum control effect of acceleration of deck could achieve $81 \%$ under the pushing ice. But the maximum displacement of deck decreases not obviously. Compared with the acceleration, the percentage of reduction is $29.8 \%$. Regarding bending ice, the vibration control effect is also very evident. It could achieve a $78 \%$ reduction in acceleration of deck; however, the maximum displacement of deck only reduces by $11 \%$. In addition, it could be found that the structure with ISO-PFDSMA brace system nearly returns to the initial position after the ice-induced excitation.

Based on Table 6, the analysis results show that ISOPFD-SMA system contributes to greater assurance of comfort of offshore platform structure, compared with ISO-SMA. Meanwhile, it plays a very important role in maintaining the stability of the whole structure and also has a good self-centering capability. Figures 16 and 17 show the time 


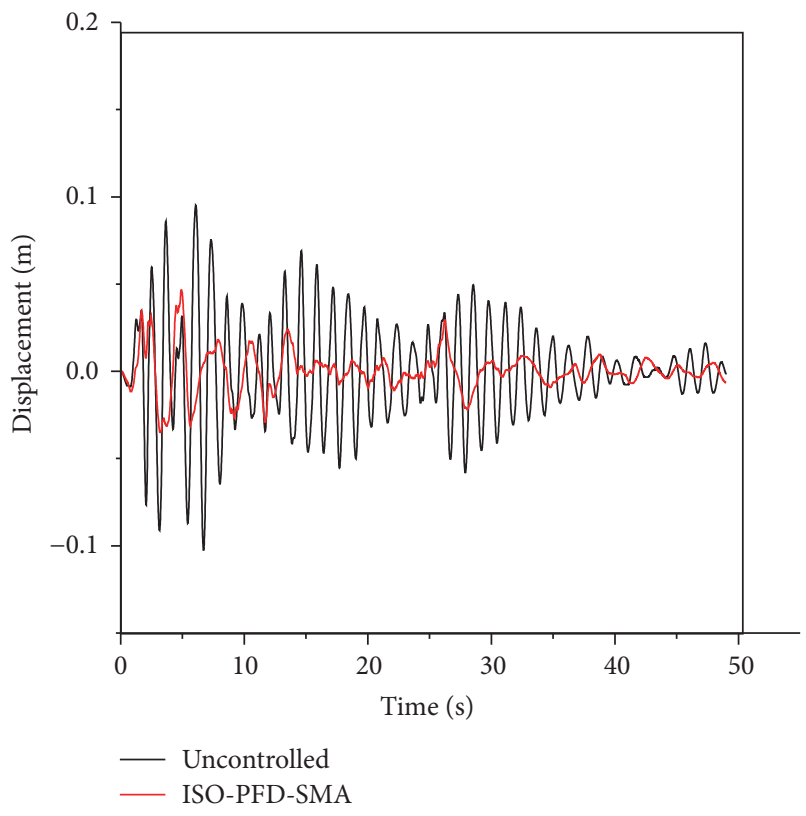

(a) Dis. of jacket cap

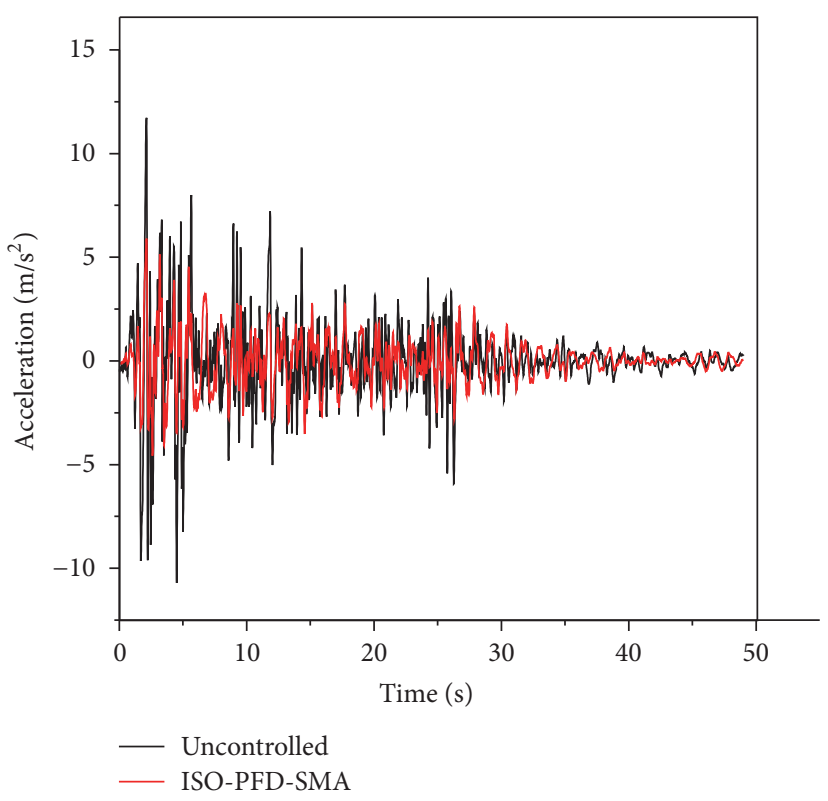

(b) Acc. of lower deck

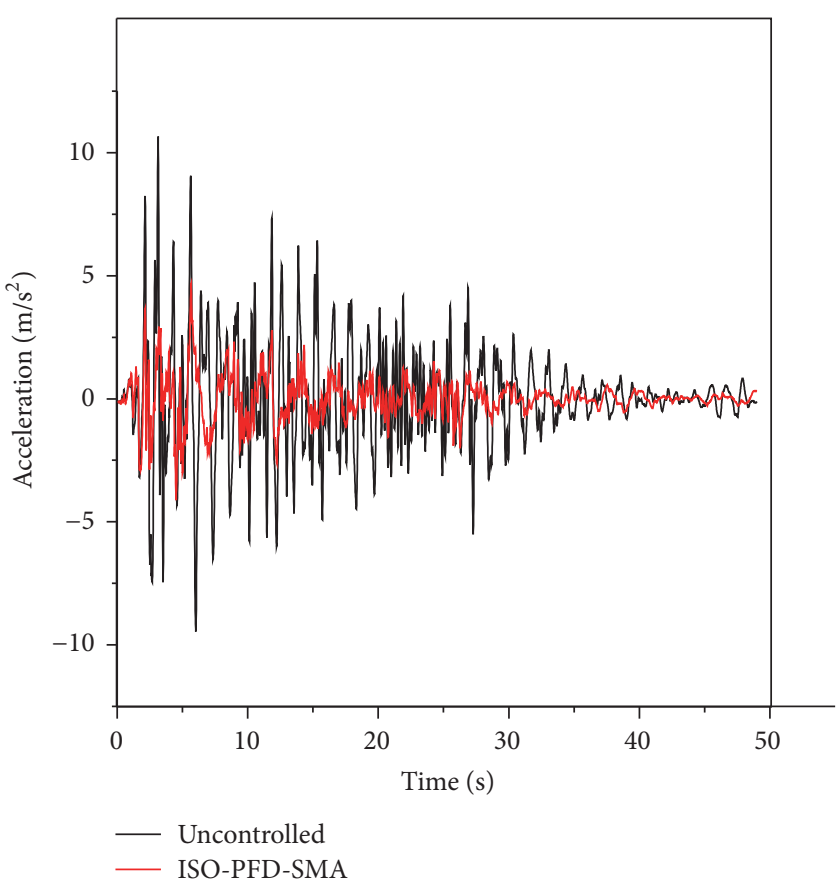

(c) Acc. of top deck

FIgURE 14: Computational response of JZ20-2MQU model under El Centro earthquake excitation.

history curves of platform structure under two ice loads, respectively.

\section{Conclusion}

This paper introduces the PFD-SMA bracing system applied in the vibration control of JZ20-2MUQ offshore platform in Bohai bay, which is subjected to action of ice and seismic excitation by numerical method. The major conclusions of this study are summarized below:

(1) ISO-PFD-SMA bracing system set between the deck and jacket cap has a better effect on mitigating vibration, compared with uncontrolled structure and even ISO-SMA bracing system, especially in the control of maximum acceleration of top and lower deck. Both the Pall friction damping and the SMA 


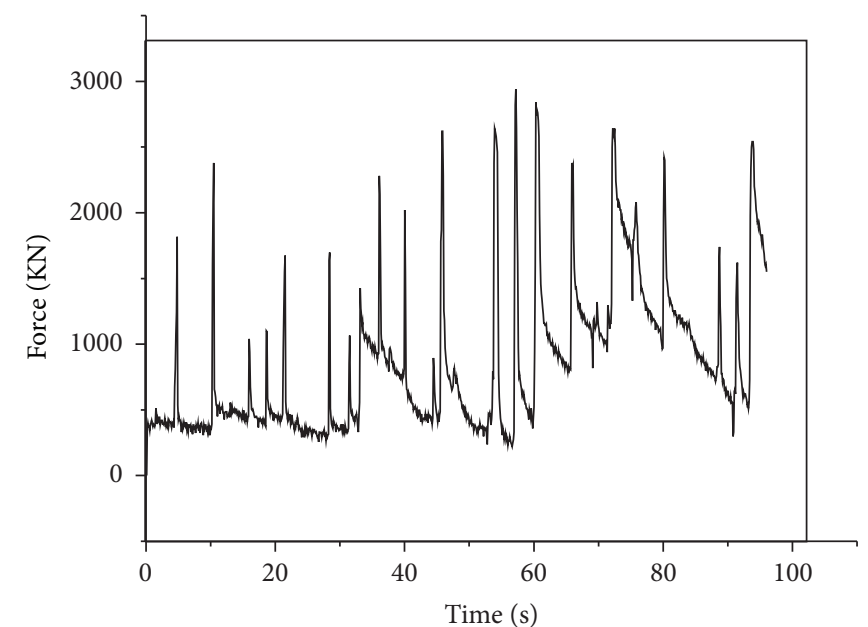

(a) Bending ice

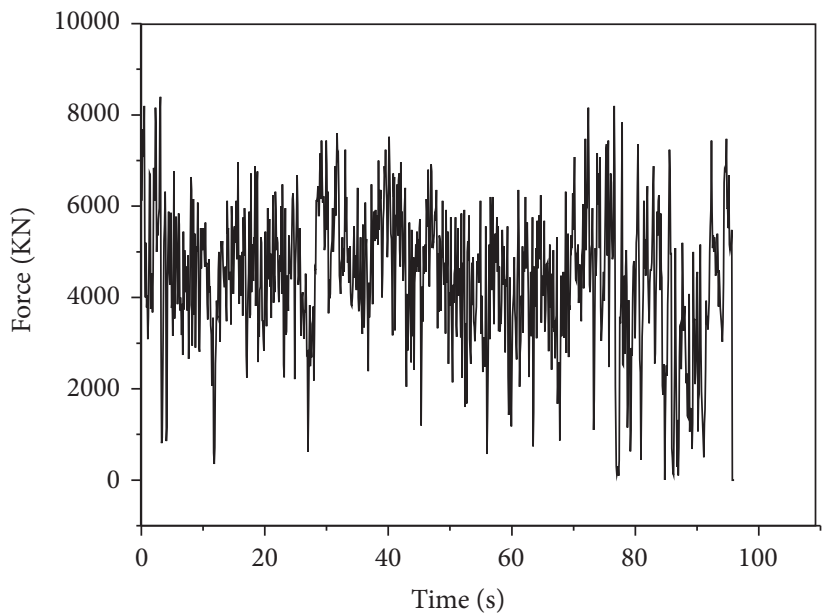

(b) Pushing ice

FIGURE 15: Time history of ice forces.

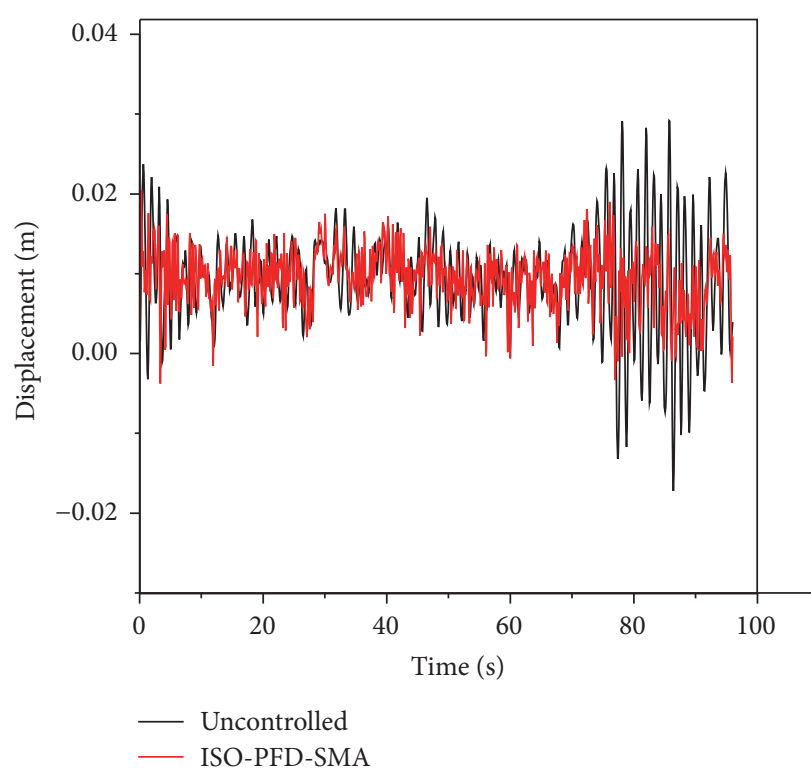

(a) Dis. of jacket cap

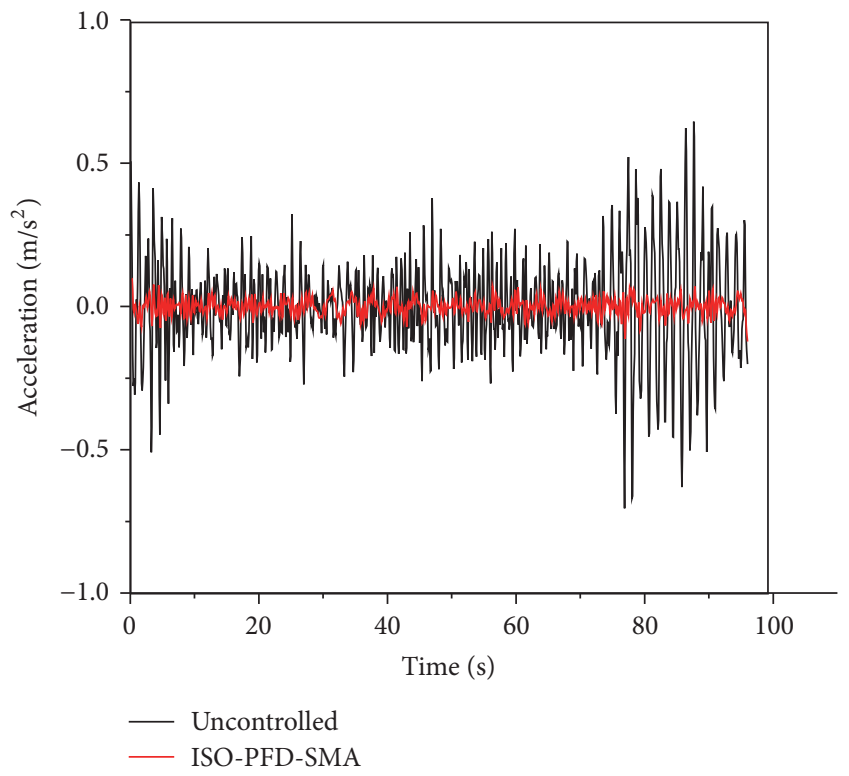

(b) Acc. of lower deck

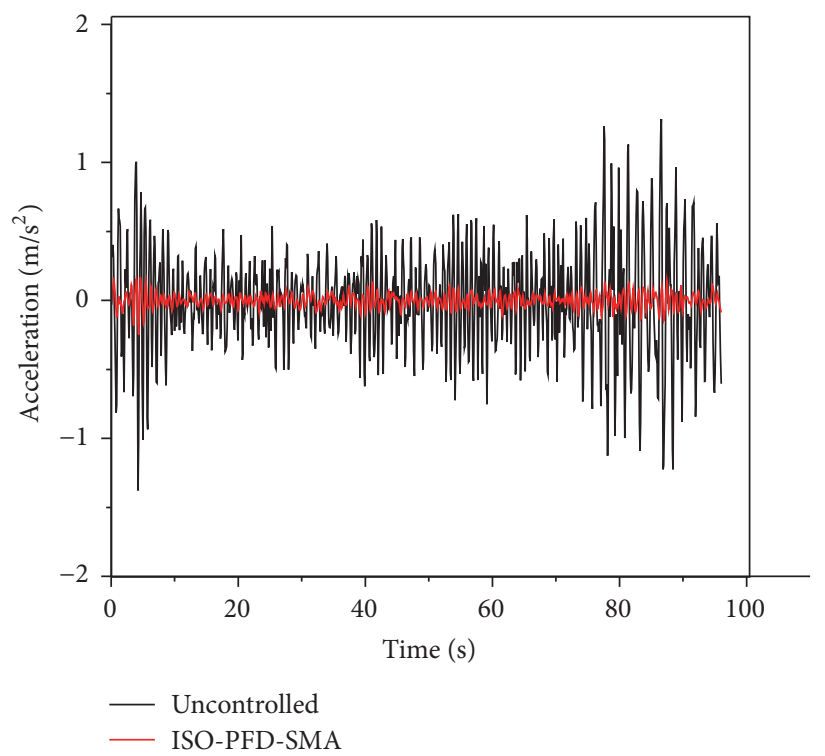

(c) Acc. of top deck

FIGURE 16: Time history curves of platform structure under pushing ice. 


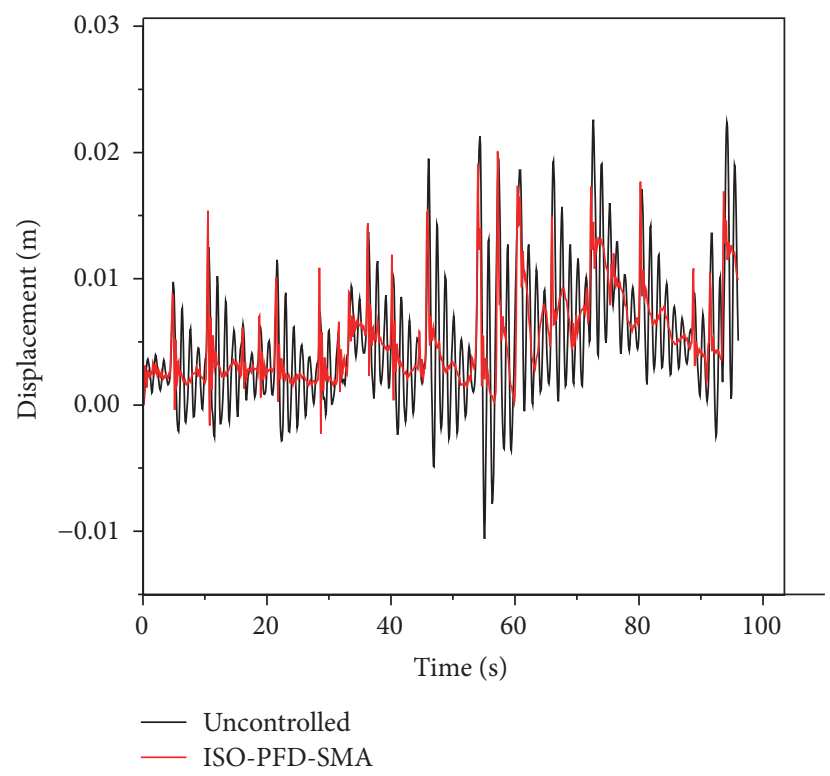

(a) Dis. of jacket cap

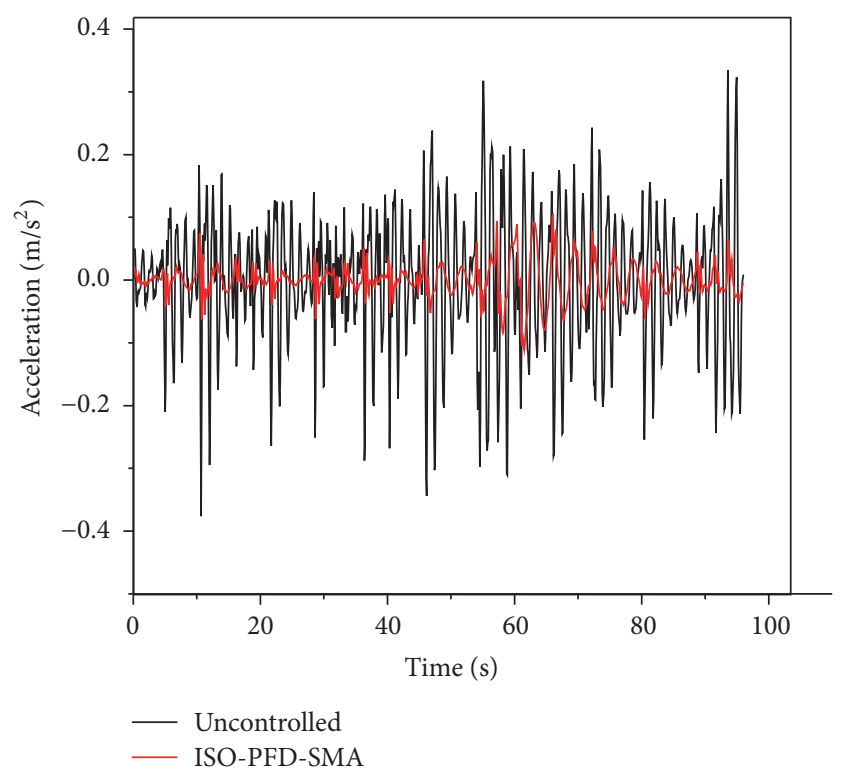

(b) Acc. of lower deck

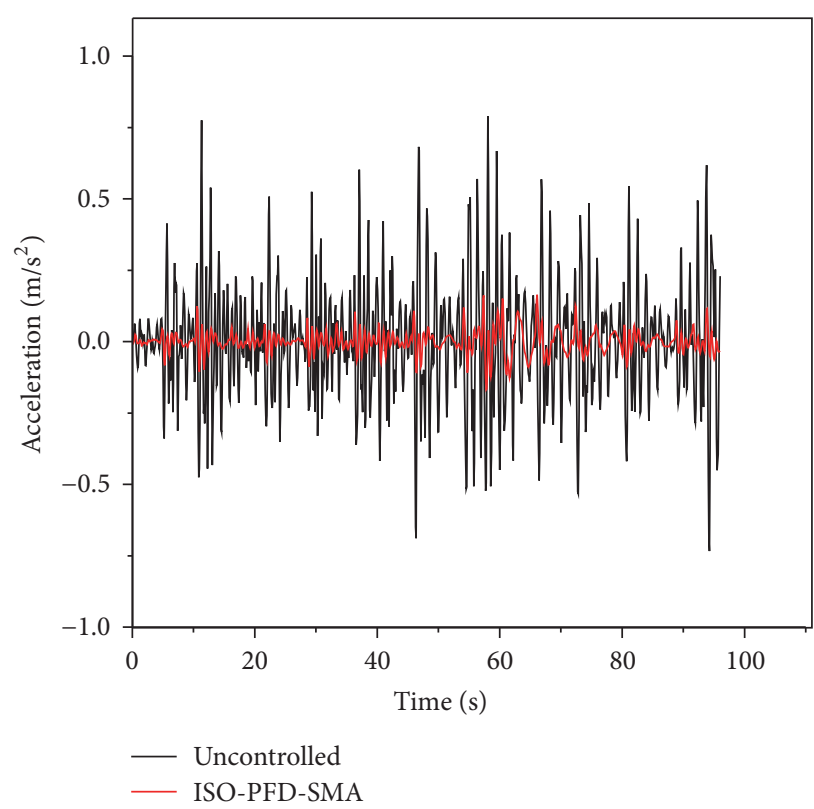

(c) Acc. of top deck

FIGURE 17: Time history curves of platform structure under bending ice.

TABLE 6: Maximum test results of ice excitation of the platform.

\begin{tabular}{lcccc}
\hline Ice load & Structural type & Displacement of jacket $(\mathrm{cm})$ & Acceleration of lower deck $\left(\mathrm{cm} / \mathrm{s}^{2}\right)$ & Acceleration of top deck $\left(\mathrm{cm} / \mathrm{s}^{2}\right)$ \\
\hline \multirow{3}{*}{ Pushing } & Uncontrolled & 2.92 & 64.52 & 131.41 \\
& ISO-SMA & $1.89(0.353)$ & $13.70(0.788)$ & $26.20(0.800)$ \\
& ISO-PFD-SMA & $2.05(0.298)$ & $12.26(0.810)$ & 79.0 \\
\multirow{3}{*}{ Bending } & Uncontrolled & 2.26 & 33.4 & $10.810)$ \\
& ISO-SMA & $2.18(0.298)$ & $10.9(0.674)$ & $18.9(0.761)$ \\
& ISO-PFD-SMA & $2.01(0.11)$ & $11.12(0.667)$ & $16.8(0.787)$ \\
\hline
\end{tabular}

Note: the figure in brackets is the percentage of effectiveness of mitigating vibration which is equal to (uncontrolled structure - control structure)/uncontrolled structure). 
bracing consume a portion of energy, respectively. So, combining the two parts, the desired effect in vibration control will be achieved.

(2) Only setting SMA bracing system may not lead to ideal results since its bracing could not give full play to their potential, because the overall stiffness of the structure is too large, and the deformation is too small. According to the results, the damping isolation system (ISO) is placed between the bottom of the deck and the top of the jacket structure, which could enhance the energy consumption and make the SMA bracing system become fully effective.

\section{Competing Interests}

The authors declare that there is no conflict of interests regarding the publication of this paper.

\section{Acknowledgments}

The authors acknowledge the financial support by the National Natural Science Foundation of China (51378271), Taishan Scholar Priority Discipline Talent Group program funded by the Shandong Province, and Qingdao Construction Commission funds for development (JK2015-13).

\section{References}

[1] W. Wei, Research on sEismic Damage States of Jacket Offshore Platform Structures, Ocean University of China, 2004 (Chinese).

[2] M. Dolce, D. Cardone, and R. Marnetto, "SMA Re-centering devices for seismic isolation of civil structures," in SPIE Proceedings of the Smart Systems for Bridges, Structures, and HighwaysSmart Structures and Materials, vol. 4330, pp. 238-249, SPIE, Newport Beach, Calif, USA, March 2001.

[3] M. Dolce, D. Cardone, and F. C. Ponzo, "Shaking-table tests on reinforced concrete frames with different isolation systems," Earthquake Engineering and Structural Dynamics, vol. 36, no. 5, pp. 573-596, 2007.

[4] S. A. Motahari, M. Ghassemieh, and S. A. Abolmaali, "Implementation of shape memory alloy dampers for passive control of structures subjected to seismic excitations," Journal of Constructional Steel Research, vol. 63, no. 12, pp. 1570-1579, 2007.

[5] M. Speicher, D. E. Hodgson, R. Desroches, and R. T. Leon, "Shape memory alloy tension/compression device for seismic retrofit of buildings," Journal of Materials Engineering and Performance, vol. 18, no. 5-6, pp. 746-753, 2009.

[6] O. E. Ozbulut, P. N. Roschke, P. Y. Lin, and C. H. Loh, "GA-based optimum design of a shape memory alloy device for seismic response mitigation," Smart Materials and Structures, vol. 19, no. 6, 2010.

[7] A. M. Sharabash and B. O. Andrawes, "Application of shape memory alloy dampers in the seismic control of cable-stayed bridges," Engineering Structures, vol. 31, no. 2, pp. 607-616, 2009.

[8] S. Moradi and M. S. Alam, "Feasibility study of utilizing superelastic shape memory alloy plates in steel beam-column connections for improved seismic performance," Journal of Intelligent Material Systems and Structures, vol. 26, no. 4, pp. 463-475, 2015.
[9] B. Wu, J. Zhang, and J. Ou, "Experimental research and numerical analysis of Pall-typed frictional dampers," Journal of Building Structures, vol. 24, no. 2, pp. 7-13, 2003 (Chinese).

[10] J. Zhang, Y. Liu, Y. Gao, and J. Han, "Experimental research of PFD-SMA support system," Applied Mechanics and Materials, vol. 71-78, pp. 4521-4524, 2011.

[11] Annual report of ice forces measurement on JZ20-2MUQ jacket platform, Bohai Inspection Company for Offshore Structure, Institute of Engineering Mechanics, China Seismological Bureau, 1995 (Chinese).

[12] JZ20-2MUQ platform structure design report, China Offshore Oil Engineering Co., Ltd, 1990.

[13] K. Bargi, S. R. Hosseini, M. H. Tadayon, and H. Sharifian, "Seismic response of atypical fixed jacket-type offshore platform (SPD1) under sea waves," Open Journal of Marine Science, no. 1, pp. 36-42, 2011.

[14] J.-G. Zhang and A.-Z. Lu, "Hysteretic behavior of advanced PFD-SMA frictional damping brace system," Journal of Central South University (Science and Technology), vol. 42, no. 10, pp. 3157-3163, 2011 (Chinese).

[15] Q. Yue and X. Bi, "Ice-induced jacket structure vibrations in Bohai Sea," Journal of Cold Regions Engineering, vol. 14, no. 2, pp. 81-92, 2000.

[16] J. Ou, X. Long, Q. S. Li, and Y. Q. Xiao, "Vibration control of steel jacket offshore platform structures with damping isolation systems," Engineering Structures, vol. 29, no. 7, pp. 1525-1538, 2007. 

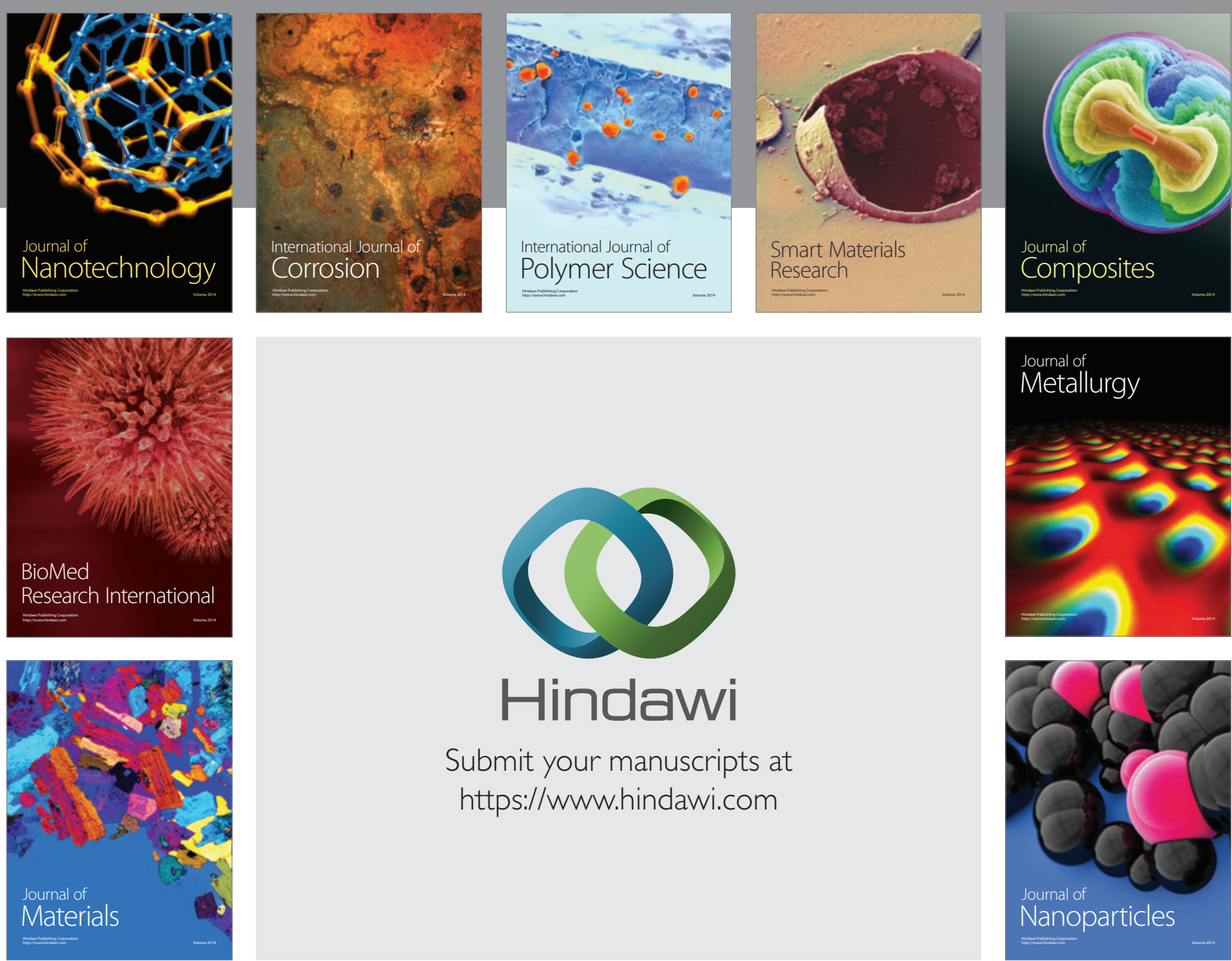

\section{Hindawi}

Submit your manuscripts at

https://www.hindawi.com

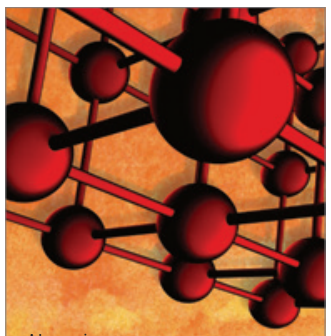

Materials Science and Engineering
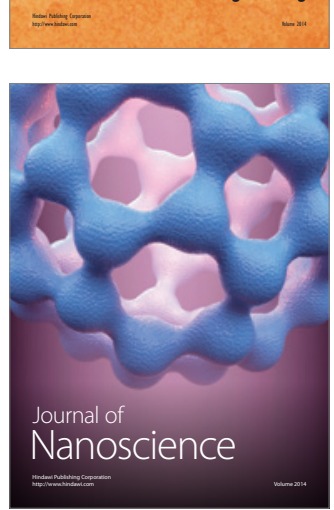
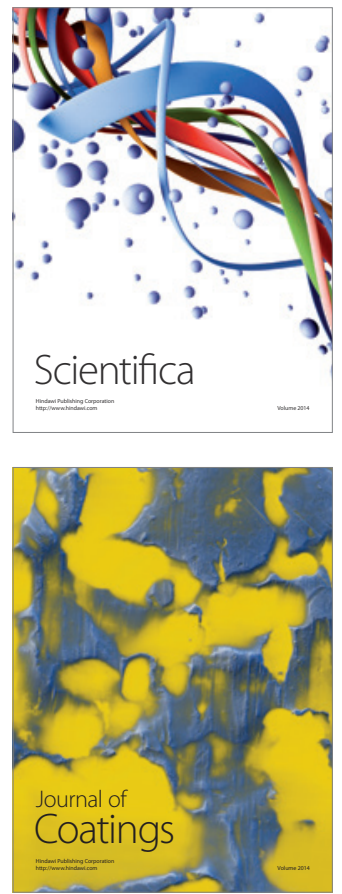
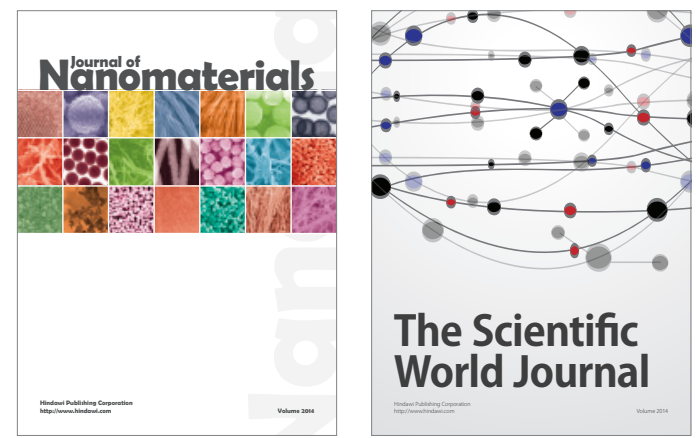

The Scientific World Journal
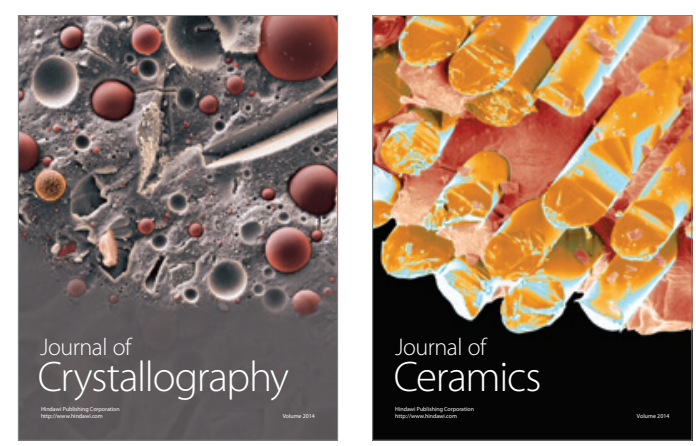
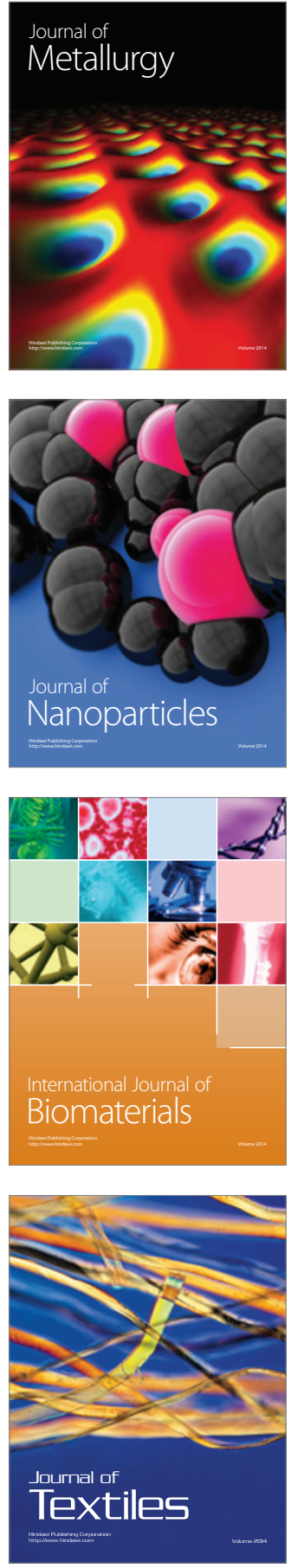